\title{
Demo backs animal lab in Oxford
}

\section{OXFORD}

Hundreds of scientists and students took to the streets of Oxford last weekend to march in favour of the city's new biomedical lab. The rally was the first time that proponents of animal testing have come out en masse to support their cause. It happened in response to threats from animal liberationists who claim that anyone associated with the University of Oxford is a legitimate target for physical violence.

The building of the Oxford lab has been hampered by persistent threats from animalrights extremists. The project has been the target of regular protests by antivivisection campaigners, but previously only a handful of researchers had raised their voices to support the lab - most of its backers, including the university itself, had remained silent on the issue.

The event, held on 25 February and attended by around 600 marchers, represents a change of strategy amid swelling grassroots support for the lab and growing indignation over the intimidating tactics of animal-rights extremists. ${ }^{\alpha}$ The university was not keen on
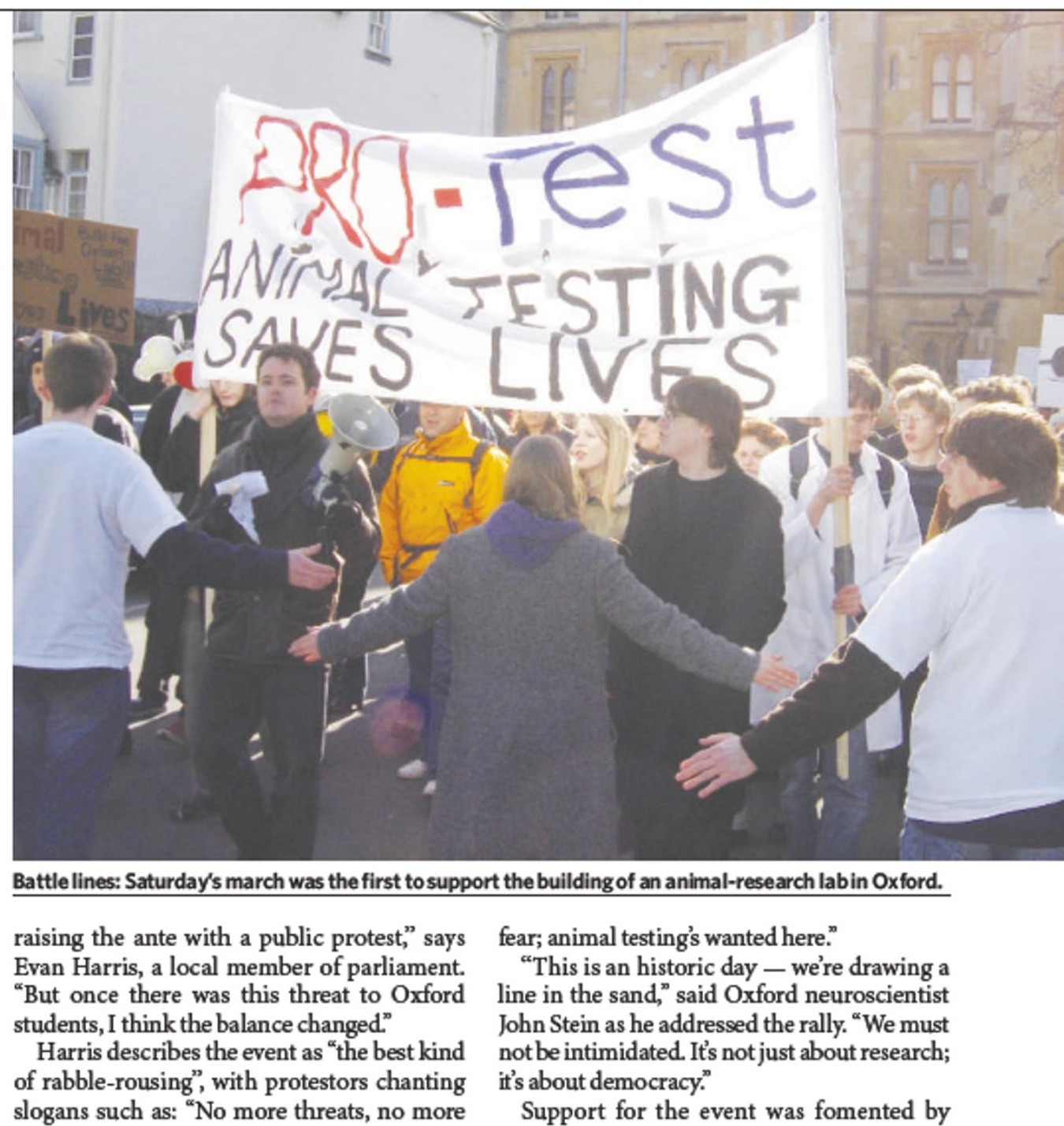
Laurie Pycroft, a 16-year-old blogger who was moved by what he saw as the one-sidedness of the animal-research debate. Until now, public demonstrations have been the preserve of groups opposed to animal research; scientists have mostly kept their heads below the parapet, for fear of personal reprisals. Pycroft created a research-advocacy website called Pro-Test, under whose banner the rally took place. "I'm extremely proud of the turnout, he told Nature. "I would have been happy with 50 people."

Meanwhile, about 150 antivivi-

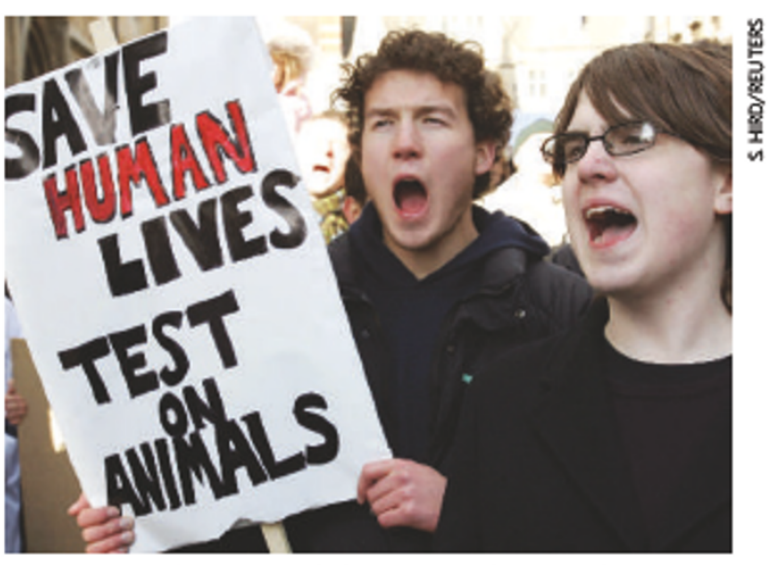

Laurie Pycroft (right) founded Pro-Test and arranged the rally. section campaigners mounted an opposing demonstration. This event, culminating in a rally at the exact spot where pro-research campaigners had mustered just hours earlier, was part of a series of demonstrations by the animal-rights group Speak.

Demonstrators at the Speak rally noted the emergence, for the first time, of large-scale public opposition to their views. One demonstrator called for the issue to receive even wider coverage now that battle lines have been formally drawn. ${ }^{\alpha} \mathrm{We}$ want to see a fair and unedited debate on prime-time television," he said.

It is a debate that traditionally has been played out in actions rather than words. The Oxford lab recently endured an 18-month hiatus in construction after the building company Walter Lilley pulled out in response to bad publicity and diving share prices. Other research facilities, such as Huntingdon Life Sciences near Cambridge, have also been subjected to intimidating tactics and violence from extreme animal-rights groups.

Speaking at the Pro-Test event, Simon Festing, director of the Londonbased Research Defence Society, called animal research a "moral ing ${ }^{\prime}$. And Oxford neuroscientist Tipu Aziz said the march was aimed at ${ }^{\text {defending our }}$

For others, the event was about standing up against what is perceived as bullying from extremists. "We're sick of the intimidation," says postgraduate research student Kristina Cook. 'It's amazing how many people support what we do but are afraid."

Michael Hopkin choice" and "a price worth payright to better humanity's plight". minister Tony Clemens, which included critical quotes about Clemens's acceptance of privatization was pulled by the management.

Jerome Kassirer, a member of the CMAI'seditorial board, points out that the journal has beendoing well, making Morris's call for a change seem oddly timed: "Given that the journal wasgetting better, was more respected, and its impact factor wasgoing up, it's hard to escape the conclusion that they were fired for political reasons."

Fiona Godlee, editor of the British Medical Journal, says shew as "shocked and saddened" by the news. She worries that the CMAJ may now recede into relative obscurity. "I think it is extremely damaging for the reputation of the journal."

Godlee hopes the firingswill stiffen the resolve of journal editors to fight for a strong wall between their editorial content and the politics of home associations. "It is beholden on editors in general to hold the line for the sake of maintaining independent scientific voices around the world."

Also "very concerned" about the sackings is Shabbir Alibhai, a specialist in cancer and geriatrics at the University of Toronto and member of the
CMAJ's reader panel. But Alibhai says the episode raises questions about the role of journal editors, particularly when writing editorials. "Who is the editor representing when he or she pens words?" he asks. "The readers? The as sociation? The journal? Or just the editors?"

Meanwhile editorial board member Philip Devereaux is widely distributing a petition to reinstate the editors. "This is one of the most fundamental battles, and it must be fought," he says. "It's not just because John and Anne Marie are really nice people." Emma Marris
ON THE RECORD "Whowould have thought you'd have standing room only at ageek event?"

Immunologist John Cohen is astonished at how CaféScientifique - aseries of informal debates with scientists - has taken off in Colorado.

Source: New York Times

\section{SCORECARD} Dog turds
ACalifornia company
announces plans to use a'methane digester' to extract energy from faeces scooped up at a popular SanFrancisco park.

1 Thermal underwear Employees at Japan's environment ministry bundle up to stay warm, after turning off the heat to help meet the country's targets for greenhouse-gasemissions.

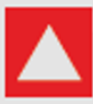
Blackbeard Engineers are building a sand dune underwater to protect what is believed to be the famedpirate's ship, sunk in 1718 off the coast of North Carolina.

\section{DATAPOINT}

How much dopeople in different countries care about science? A glimpse comes from the Science and Engineering Indicators 2006 , published by the USNational Science Board. People indicated their interest in new scientific discoveries on a scale from 1 to 100 .

\section{China}

United States

Europe

South Korea

Japan

\section{NUMBER CRUNCH}

Earth crossed anotherpopulation milestone last weekend.

\section{5 billion is the world's} population, as of 25 February.

131 million people will be bornin 2006.

57 million people will die in 2006.

Source: US Census Bureau 